This item was submitted to Loughborough's Research Repository by the author.

Items in Figshare are protected by copyright, with all rights reserved, unless otherwise indicated.

\title{
Spray-freeze-drying of whey proteins at sub-atmospheric pressures
}

PLEASE CITE THE PUBLISHED VERSION

http://dx.doi.org/10.1051/dst/2010013

PUBLISHER

(c) EDP Sciences / @ INRA

\section{VERSION}

AM (Accepted Manuscript)

LICENCE

CC BY-NC-ND 4.0

REPOSITORY RECORD

Anandharamakrishnan, C., Chris D. Rielly, and A.G.F. Stapley. 2011. "Spray-freeze-drying of Whey Proteins at Sub-atmospheric Pressures". figshare. https://hdl.handle.net/2134/8342. 
This item was submitted to Loughborough's Institutional Repository (https://dspace.lboro.ac.uk/) by the author and is made available under the following Creative Commons Licence conditions.

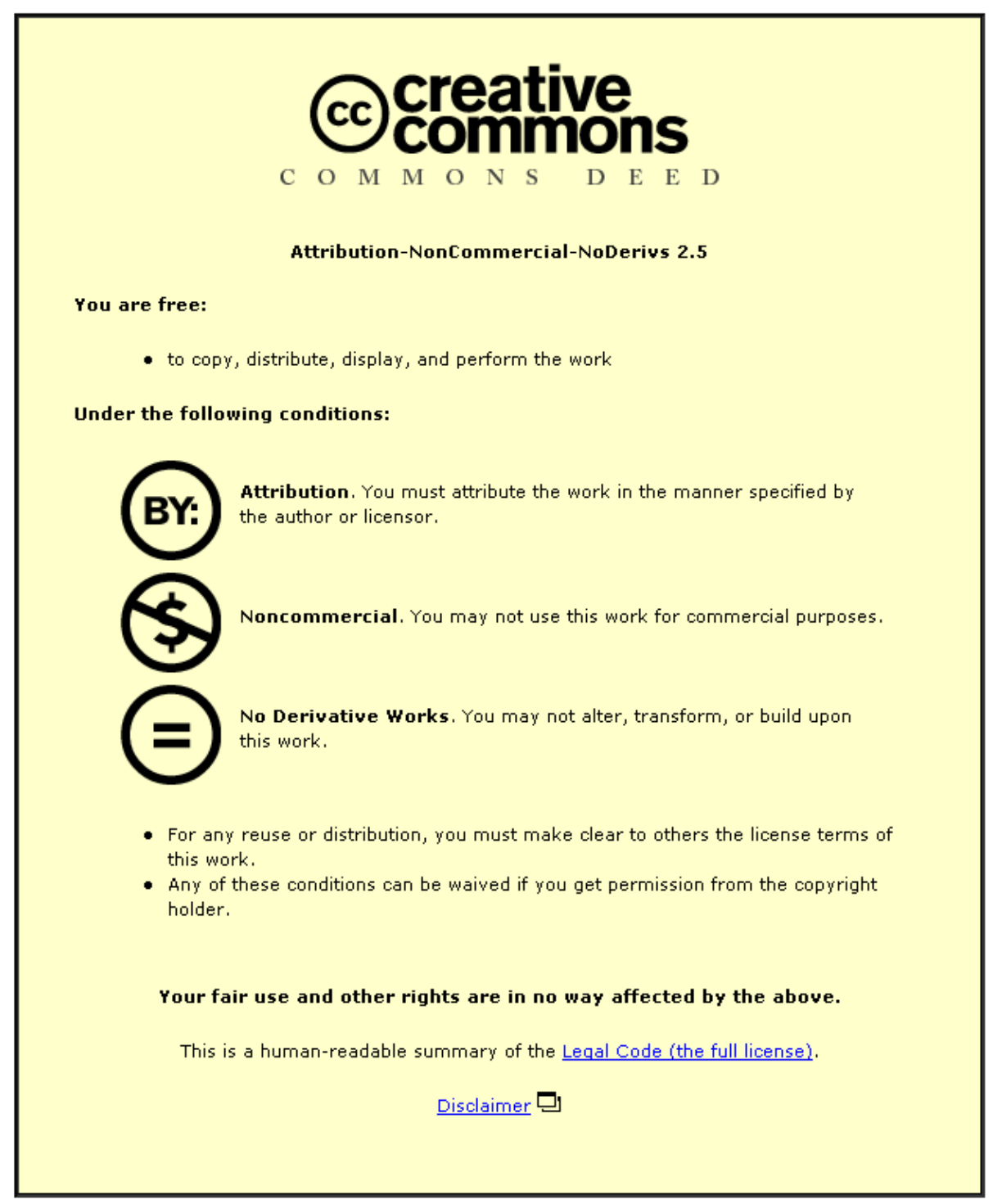

For the full text of this licence, please go to: http://creativecommons.org/licenses/by-nc-nd/2.5/ 


\title{
SPRAY-FREEZE-DRYING OF WHEY PROTEINS AT SUB- ATMOSPHERIC PRESSURES
}

\author{
Chinnaswamy ANANDHARAMAKRISHNAN ${ }^{1}$, Chris D. RIELLY \\ and Andrew G. F. STAPLEY* \\ Department of Chemical Engineering, Loughborough University, \\ Loughborough, Leicestershire, LE11 3TU, UK.
}

Running head: Spray-Freeze-Drying of Whey Proteins

\footnotetext{
${ }^{*}$ Corresponding author: Dr. A.G.F. Stapley

E-mail:A.G.F.Stapley@Lboro.ac.uk; Tel.: +44 (0)1509 222525

${ }^{1}$ Present Address: Central Food Technological Research Institute, Mysore, India
} 


\section{ABSTRACT}

2 Spray-freeze-drying (SFD) involves spraying a solution into a cold medium,

3 and freeze-drying the resultant frozen particles, which can be performed by

4 contacting the particles with a cold, dry gas stream in a fluidized bed, typically

5 at atmospheric pressure. This enables much faster drying rates than are

6 usually possible by conventional freeze-drying, due to the small particle sizes

7 involved. However, the quantities of gas required for atmospheric fluidized

8 bed freeze-drying are prohibitively expensive. This has led to a process

9 modification whereby fluidization is performed at sub-atmospheric pressures,

10 which still allows rapid freeze-drying, but using much less gas. This study

11 demonstrates the fluidized bed spray-freeze-drying technique at sub-

12 atmospheric pressures ( 0.1 bar) using whey protein isolate solution $(20 \% \mathrm{w} / \mathrm{w}$

13 solids) at gas inlet drying temperatures ranging from $-10{ }^{\circ} \mathrm{C}$ to $-30{ }^{\circ} \mathrm{C}$. The

14 process yields a powder consisting of highly porous particles and shows little

15 loss of solubility for $\beta$-lactoglobulin and $\alpha$-lactalbumin, the principal proteins in

16 the isolate. A wet basis moisture content of $8.1 \%$ was achieved after freeze-

17 drying at $-10{ }^{\circ} \mathrm{C}$ for only 1 hour, whilst at $30{ }^{\circ} \mathrm{C}$ a longer drying time (100

18 minutes) produced a wetter product (14\% w.b.). 


\section{1. INTRODUCTION}

Freeze-drying is a popular method of producing shelf stable particulate

3 products, and is of particular value for drying thermally sensitive materials

4 (usually biologically based), which can be heat damaged by higher

5 temperature methods, such as spray-drying. Porous structures are formed by

6 the creation of ice crystals during the freezing stage, which subsequently

7 sublime during the drying stage and this often leads to good rehydration

8 behaviour of the powdered product [20]. However, freeze-drying involves high

9 capital and operating costs, due to the low temperatures, high vacuum, and

10 long residence times required. It has been found that freeze-drying times vary

11 approximately with the square of the sample thickness $[13,8]$. Hence one

12 solution to this problem of long residence times is to reduce the dimensions of

13 the material, i.e. use smaller particle sizes. This is the basis of the spray-

14 freeze-drying technique, which is a two-step process of (i) spray-freezing

15 followed by (ii) freeze-drying. Spray-freezing involves the atomization of a

16 liquid stream in a manner similar to spray drying, but then freezing the spray.

17 At present, three classes of method are used for spray-freezing: (i) spray-

18 freezing into vapour (SFV) [10, 21] (ii) spray-freezing into vapour over liquid

19 (SFV/L) $[12,17]$ and (iii) spray-freezing into liquid (SFL) $[5,18]$. The second

20 freeze-drying step is often achieved by conventional freeze-drying, in which

21 the latent heat of sublimation is supplied by conductive or radiative heating.

22 However, this is difficult to apply uniformly to a powder, so as to take

23 advantage of the small particle size and reduced drying times, without the risk

24 of particle melting and collapse. Instead an alternative approach of contacting

25 the articles with cold, dry gas in a fluidized bed can be used. 
The concept of freeze-drying using atmospheric air was first published

2 in the 1950's [14], but the use of a fluidized bed is more recent [13] and does

3 not appear yet to have had widespread application to freeze-dry powders. The

4 majority of published work on spray-freeze-drying (SFD) has been in the

5 pharmaceutical area where freeze-drying has been performed conventionally

6 on trays. An exception has been the work of Mumenthaler and Leuenberger

$7 \quad[15,10]$ and later Wang et al. [21] who used cold desiccated gas to first freeze

8 and then dry the spray in an integrated fluidized bed at atmospheric pressure.

9 This process is able to work by maintaining a very low dew point of water

10 within the system, which allows ice to sublime even at atmospheric pressure.

11 Due to the small particle sizes drying times of 2 hours were able to be 12 achieved.

A problem with the atmospheric spray-freeze-drying process, however

14 is the very large quantities of cold dry gas that need to be circulated through

15 the bed. As freeze-drying must be performed below the collapse temperature

16 of the material (which can be as low as $-30^{\circ} \mathrm{C}$ ) the ice phase exerts an

17 extremely low vapour pressure (e.g. $38.96 \mathrm{~Pa}$ at $-30{ }^{\circ} \mathrm{C}$ ). Even if freeze-

18 drying had a negligible resistance for mass transfer from within the particle to

19 the gas phase (such that the exit gas of the fluidized bed was at the saturation

20 value of the particle temperature), from the Ideal Gas Law it would require

21 approximately $4200 \mathrm{~kg}$ of bone dry gas to pass through the bed in order to

22 sublime $1 \mathrm{~kg}$ of ice. Although this can be partly offset by recirculating (and

23 drying) the gas, this is a huge quantity of gas to have to be supplied to the

24 process. The refrigeration and drying requirements for such a mass of gas to

25 meet the required specification are considerable and severely harm the 
1 economics of the process. A further consideration is that to pass this mass of

2 gas through the bed in a reasonable time (say a few hours) requires a very

3 large gas volume flow rate and hence a high velocity in the fluidised bed. This

4 leads to particles being elutriated and subsequently these must be caught by

5 a gas-filter, as reported by Mumenthaler and Leuenberger [15]. Although this

6 is a feasible means of drying the particles, it does render the fluidized bed

7 (with its high heat and mass transfer ability) redundant.

$8 \quad$ 1.1. Sub-atmospheric spray-freeze-drying

One means of alleviating the problem of circulating large mass flow 10 rates of dry gas, which has recently been considered in the literature, is to 11 apply a partial vacuum to the process $[1,11]$. The gas is, after all, merely an 12 inert heat transfer medium and plays no part in determining the driving force 13 for mass transfer. As an example, if the process is operated at $-30{ }^{\circ} \mathrm{C}$ and an 14 absolute pressure of 0.1 bar then the mass of saturated gas required would 15 be approximately $420 \mathrm{~kg}$ (i.e. one tenth of the amount at 1 bar). Although a 16 vacuum capability increases the capital cost and operational difficulty of the 17 plant, it also significantly reduces the mass of dry gas required. An initially 18 rather startling result is that the volume of inert gas to sublime $1 \mathrm{~kg}$ of ice 19 (assuming saturation) is independent of the system pressure (in the above 20 examples approximately $2900 \mathrm{~m}^{3}$ of gas would be required in both cases). 21 This is because even though there is ten-fold reduction in the mass of gas 22 required at 0.1 bar, the reduction in pressure by a factor of ten means that the 23 gas is also ten times less dense. By the same token to extract this $1 \mathrm{~kg}$ of ice, 24 the gas velocity passing through the bed would also be the same irrespective 25 of total system pressure. However, the lower density at lower pressures would 
1 reduce the inertial (non-viscous) drag forces on the particles, and if a low

2 enough pressure were used then particles would not be elutriated from the 3 bed.

Thus lower pressures are desirable as they decrease the mass of gas

5 required and reduce the number of particles being swept from the bed. This

6 might suggest approaching the pressures used in conventional freeze-drying

7 (with effectively no gas in the system), however enough gas needs to be

8 present to supply the latent heat of sublimation.

9 In this study, a spray-freeze-drying rig has been constructed, in which

10 the fluidized bed freeze-drying section is capable of operating at reduced

11 pressures [1], as shown in Figure 1. The fluidized bed is fitted with

12 thermocouples to measure the temperatures of the particle bed and the exit

13 gas (located approximately $3 \mathrm{~cm}$ above the bed). These provide a

14 measurement of the "wet-bulb" depression of the particles, and thus provide

15 an indication of the drying rate. The process is demonstrated by spray-freeze-

16 drying a solution of whey protein isolate.

\section{2. MATERIALS AND METHODS}

\subsection{Whey Protein Solution Preparation}

Whey protein isolate (WPI) powder was obtained from Ultimate

20 Nutrition (Fleetwood, Lancashire, UK) and the manufacturer claims that $99 \%$

21 of the whey proteins are undenatured. The $20 \%(\mathrm{w} / \mathrm{v})$ whey protein solution

22 was prepared at room temperature by dissolving $200 \mathrm{~g}$ of powder in $0.7 \mathrm{~L}$

23 distilled water. This mixture was gently stirred in a laboratory mixer (Silverson)

24 for 10 minutes to dissolve all the whey proteins in water and finally made up to 
$11 \mathrm{~L}$ by the addition of distilled water. The mixture was kept for a consistent

2 period of 30 minutes before spray-freeze-drying, in order for the protein to

3 hydrate.

4 2.2. Spray-freeze-drying equipment

The spray-freeze-drying system used here differs from that of

6 Leuenberger's group [11, 15] in that spray freezing and freeze drying are

7 carried out in two separate vessels. Spray frozen particles are first formed by

8 spraying the concentrate into a cooled spray chamber $(1.5 \mathrm{~m}$ high $\times 0.8 \mathrm{~m}$

9 diameter). The chamber had been previously purged with nitrogen gas from a

10 cylinder before cooling with liquid nitrogen from a dewar. The spray chamber

11 wall temperature and gas temperature were then adjusted to $-85 \pm 2{ }^{\circ} \mathrm{C}$ by

12 regulating the ratio of nitrogen from the two sources. Atomization was

13 achieved using a hydraulic nozzle (WL053 ex Bete, Lewes, UK) using a liquid

14 feed from a feed tank pressurised with nitrogen gas at 8 bar gauge pressure.

15 To avoid the liquid feed freezing in the nozzle, the nozzle and approaching

16 pipework were kept warm by circulating warm air around them, with only the

17 nozzle tip being exposed to the cold chamber gas. The liquid feed rates were

18 measured for each experiment by measuring the change in volume of feed in

19 the feed vessel over time. The measured liquid feed flow rate for all the trials

20 was $0.0125 \mathrm{~kg} \cdot \mathrm{s}^{-1}$. The frozen particles were collected from the outlet of the

21 chamber in a cooled expanded polystyrene box. The particles were then

22 loaded into the freeze-dryer, which consisted of a polycarbonate cylinder

23 inside a stainless steel vacuum vessel (see Figure 2). The bottom of the

24 polycarbonate cylinder (16 cm high x $15 \mathrm{~cm}$ diameter) was fitted with a 2-mm

25 thick polyethylene sheet (Vyon F2, Porvair Technology) to act as a distributor 
1 plate and the top of the vessel was fitted with a fine mesh to allow a low

2 temperature gas flow through the particle bed whilst retaining the particles

3 within the drying chamber.

As well as offering sub-atmospheric operation the equipment used here

5 does not recycle the gas but uses nitrogen gas (sourced from a liquid nitrogen

6 dewar) in a "once through" configuration. The temperature of the gas (which is

7 warmed as it travels into the rig) is regulated by adjusting the flowrate. The

8 temperatures of the inlet gas, the bed and the fluidizing gas just above the

9 bed were measured by type $\mathrm{T}$ thermocouples. The depth of the bed was

10 approximately $1 \mathrm{~cm}$. For the production of freeze-dried whey a constant inlet

11 gas temperature was used. This resulted in the particle temperatures

12 gradually rising during the drying cycle. A period of 10 minutes was required in

13 order to stabilise the operating conditions at the beginning of the process (as

14 the particles enter the chamber at a much colder temperature). The chamber

15 was maintained under a partial vacuum using a rotary vane oil-sealed vacuum

16 pump (Werner Rietschle model CLF100, Schlopfheim, Germany) at the outlet

17 which delivers a nominal gas flowrate of $100 \mathrm{~m}^{3} \cdot \mathrm{h}^{-1}$ though the bed. The

18 chamber pressure was measured using a Druck PMP4070 pressure sensor.

19 All instrumentation was connected via a Datascan 7321 data logger to a PC

20 running DASYLAB data acquisition software. The resulting spray-freeze-dried

21 product was analysed for moisture content, particle size and morphology and

22 the loss of solubility of the proteins. 


\subsection{Moisture content}

The average moisture content of the spray-freeze-dried powder was

3 measured gravimetrically. A known mass of sample (approximately $0.5 \mathrm{~g}$ ) was

4 placed in an aluminium foil pan and dried in a vacuum oven at $105^{\circ} \mathrm{C}$ for a

5 period of 12 hours. The sample was then removed and immediately weighed

6 to limit water absorption from the atmosphere. The initial and final weights

7 were then used to calculate the wet basis moisture content. The experiments

8 were carried out in triplicate and average and standard deviation values

9 calculated.

\section{2.4. Particle size}

11 Particle size was determined by a Coulter LS 130 (Beckman Coulter, 12 High Wycombe, Bucks, UK) particle sizer, which measures particle sizes in 13 the range of $0.4-800 \mu \mathrm{m}$ using laser light scattering. Each sample was 14 dispersed in a solvent (isobutanol) to perform the measurements. The particle 15 sizes are presented as Sauter mean diameters $(\mu \mathrm{m})$ with mean and standard 16 deviation values calculated from three independent measurements.

\section{$17 \quad 2.5$. Loss of solubility}

The amounts of native $\alpha$-lactalbumin and $\beta$-lactoglobulin in the soluble

19 fraction at $\mathrm{pH} 4.6$ were determined by reversed phase high-performance liquid 20 chromatography (RP-HPLC), based on the method of Ferreira et al. [6, 7]. For 21 details of the exact method used readers are referred to 22 Anandharamakrishnan et al. [4]. The experiments were carried out in triplicate 23 for each sample and average values were taken to calculate the loss of 24 solubility from the following equation: 


$$
\% \text { loss of solubility }=\left(1-\frac{S P_{f d}}{S P_{u}}\right) \times 100
$$

2 where $S P_{f d}$ is the soluble protein in the spray-freeze-dried sample and $S P_{u}$ is

3 the soluble protein in the untreated sample.

\section{$4 \quad$ 2.6. Scanning Electron Microscopy}

Scanning Electron Microscope (SEM) images of the spray-freeze-dried

6 samples were examined using a Cambridge Stereo Scan 360 at the

7 Department of Materials Engineering at Loughborough University, UK.

\section{3. RESULTS AND DISCUSSIONS}

\section{$9 \quad$ 3.1. Temperature measurements during freeze-drying}

Table I shows drying times, measured final moisture content and

11 average particle size for the three inlet gas temperatures used in this study. In

12 general, the process yields reasonably low moisture contents, but these are

13 achieved considerably faster than the many hours usually required for

14 conventional freeze-drying (such as 40 hours for conventionally freeze drying 15 protein powders [12]). Faster drying rates are observed at higher temperatures with a drying time of only 1 hour required to produce a

17 powdered product of $8.1 \%$ at $-10^{\circ} \mathrm{C}$, whereas at $-30{ }^{\circ} \mathrm{C}$ a moisture content of 18 only $14 \%$ was achieved after 100 minutes. This is not unsurprising given the 19 larger transport coefficients and pure ice vapour pressure at the higher 20 temperatures. The drying times observed here compare favourably with those 21 previously reported in the literature $[11,15]$ for trehalose and mannitol.

Figure 3 shows inlet gas, outlet gas and particle bed temperatures for 23 an example run operating at an absolute system pressure of 0.1 bar, and 
1 using a constant gas inlet temperature of $-10^{\circ} \mathrm{C}$. A visual inspection of the

2 bed showed very mild fluidization to be taking place. It can be seen that there

3 is a significant wet-bulb depression of the particle temperature below the gas

4 temperature, and a significant change in temperature of the gas as it passes

5 through the bed. It can be seen that these temperature differences reduce as

6 time proceeds. Both indicate that a significant degree of drying is taking place

7 as convective heat transfer from the gas to the particles must be taking place

8 to overcome sublimative cooling.

9 Indications from other experiments suggest that the difference between

10 the particle and gas temperatures increases as the system pressure is

11 reduced. This is because the pressure influences the thermal mass of the

12 fluidizing gas and the heat transfer coefficient between the gas and the 13 particle bed. The variation of the rate of drying with time can be inferred from 14 the temperature measurements by assuming that the heat transfer coefficient 15 and heat transfer surface area are constant during drying, i.e.

$$
-\frac{d M}{d t}=\frac{h A\left(T_{g}-T_{p}\right)}{\lambda}
$$

17 where, $A$ is the surface area of the particles, $h$ is the heat transfer coefficient, $18 \lambda$ is the latent heat of sublimation, $T_{p}$ is the particle temperature, $M$ is the 19 mass of sample and $T_{g}$ is the gas temperature in contact with the particles.

20 This assumes that all the heat supplied is consumed by the latent heat of ice 21 sublimation. The gas temperature $T_{g}$ needs to be corrected by an amount $22 \Delta T_{\text {offset }}$ obtained at zero drying rate due to warming of gas in the fluidising 23 chamber.

$$
T_{g}=T_{\text {inlet }}+\Delta T_{\text {offset }}
$$


Spray-Freeze-Drying of Whey Proteins

1

$$
\Delta T=T_{g}-T_{p}=T_{\text {inlet }}+\Delta T_{\text {offset }}-T_{p}
$$

2 As the mass of dry whey also remains constant the above equation can be expressed in terms of the dry basis moisture content, i.e.

4

$$
-\frac{d W}{d t}=k\left(T_{g}-T_{p}\right)
$$

5 where $\quad k=\frac{h A}{\lambda M_{d r y}}$

6 Integrating equation 5 over the whole time of the experiment yields:

$$
W_{i}-W_{f}=k \int_{0}^{t_{f}}\left(T_{g}-T_{p}\right) d t
$$

8 Thus evaluating the area under the curve of $\left(T_{g}-T_{p}\right)$ versus $t$ (see Figure 4),

9 combined with a knowledge of the initial and final dry basis moisture contents 10 enables the value of $k$ to be determined. Integrating equation 5 to intermediate times yields:

$$
W_{i}-W=k \int_{0}^{t}\left(T_{g}-T_{p}\right) d t
$$

13 Equation 8 thus offers a means of obtaining a drying curve of the material 14 under all drying regimes. This assumes that the material in contact with the 15 particle bed thermocouple is representative of the bed as a whole. It also assumes that the thermocouple measuring the "particle" temperature is not

17 influenced by the passing gas temperature. However, it may well be the case 18 that this thermocouple instead provides a weighted mean of the particle and 19 gas temperatures. This would act to reduce the observed temperature 20 difference by a certain proportion which would remain constant if the relative 21 "weights" (comprising the weighted mean) remain reasonably constant. The 
1 resulting drying curve would thus be unaffected. However, changes to the

2 relative weightings would affect the overall result and this may occur as a

3 result of changing fluidization behaviour (which becomes more lively towards

4 the end of an experiment). The different behaviour shown by experiments at -

$510^{\circ} \mathrm{C}$ and $-30^{\circ} \mathrm{C}$ (which show signs of a constant rate period) compared to

6 the experiment at $-15^{\circ} \mathrm{C}$ (which does not) may be caused by this. Thus whilst

7 the method is an effective monitoring tool it should not be relied upon for

8 highly accurate data. The drying curves obtained from this analysis are shown

9 for all three inlet gas temperatures in Figure 5, and it clearly indicates

10 gradually decreasing rates of drying of all runs, as the particle temperatures

11 gradually rise.

\subsection{Particle size analysis}

The SFD process produces Sauter mean particle diameter particle sizes in the range of 393 to $489 \mu \mathrm{m}$ (Tab. I). Larger diameter particles were found when an inlet temperature of $-10{ }^{\circ} \mathrm{C}$ was used. The particle sizes are larger than expected for this spray [1] and this is a consequence of the collection method which is biased; larger particles are more likely to drop into the collection box rather than be conveyed away on the air stream.

\subsection{Solubility analysis}

Loss of solubility of $\alpha$-lactalbumin and $\beta$-lactoglobulin were analysed using the RP-HPLC method. The chromatograms for whey protein isolate before and after spray-freeze-drying are shown in Figure 6 . The chromatograms can clearly resolve the individual peaks for $\alpha$-lactalbumin and $\beta$-lactoglobulin. From the areas of these peaks, it was determined that there was no detectable loss of solubility of $\alpha$-lactalbumin, whereas a $2 \pm 0.5 \%$ loss 
1 of solubility of $\beta$-lactoglobulin was observed after spray-freeze-drying of WPI

2 in all the trials (the variations in the $-10,-15$ and $-30{ }^{\circ} \mathrm{C}$ trials are within the

3 experimental error range). Earlier reports also indicated that $\alpha$-lactalbumin is a

4 more stable protein than $\beta$-lactoglobulin $[4,7]$. Thus only a mild loss of

5 solubility of proteins occurs during spray-freeze-drying.

\section{3.4. SEM images of spray-freeze-dried particles}

Observing the internal microstructure of the spray-freeze-dried product

8 is a useful means of validating that the dried product has been properly

9 freeze-dried and has not suffered collapse. The external surface composition

10 of the powder can also influence its properties such as, solubility, flowability

11 and stickiness. Numerous studies have been performed on the spray-dried

12 powder surface and internal structures [19, 3]. However, very few studies

13 have reported on surface and microstructures of spray-freeze-dried particles.

14 The first particle surface study was performed by Al-Hakim and Stapley [2]

15 with cryo-SEM images of spray-freeze-dried whey protein powders. More

16 complex multi-component milk powders have been recently studied by

17 Hindmarsh et al. [9] and Rogers et al. [16].

SEM images of spray-freeze-dried whey protein isolate powder are

19 shown in Figure 7. All three different inlet temperatures runs shown similar 20 particle morphologies. A typical large particle with smaller particles 21 agglomerated on to its surface is shown in Figure 7(a).

22 The surfaces of the particles in Figures 7(a), (b) and (d) are generally

23 smooth, containing small pores and an occasional surface blemish. A

24 magnification of one of these blemishes surface is shown in Figure 7(c), which 25 reveals a porous structure inside the particle. This is to be expected from a 
1 freeze-dried product, and is a consequence of ice crystal formation during the

2 freezing step, which sublimes during freeze-drying to leave a porous structure.

3 This confirms that collapse has not occurred during freeze-drying. Due to the

4 very fast rates of freezing at this size scale the ice crystals-and hence pore

5 sizes-are much smaller than normally found in freeze-dried products. Figure

$67(\mathrm{c})$ shows this at greater magnification, whereas Figure 7 (e)-(f) show the

7 internal pore structure from some particles which have fragmented. These

8 microstructures are similar to those found by Hindmarsh et al. [9] and Rogers

9 et al. [16]. Figure 7(e) shows a bubble inside a particle. The bubble is 10 probably the result of nitrogen gas being releasing from solution during

11 atomisation, as the feed solution is held under pressure using compressed

12 nitrogen in the feed chamber. Yu et al. [22] also reported that small bubbles 13 were generated during atomisation and they observed that bubbles were 14 presented in the particles during spray-freezing in vapour over liquid (SFV/L) 15 process.

\section{CONCLUSIONS}

The results presented here show that the spray-freeze-drying

18 technique has been shown to work well, by performing the freeze-drying step

19 at sub-atmospheric pressures ( 0.1 bar absolute). Not only has rapid drying 20 been obtained (of the time scale of one hour), but the particles were not eluted

21 from the fluidized bed and a significantly smaller mass of gas was used than 22 would have been the case if operated at atmospheric pressure. Dryer particle 23 could probably be obtained if the inlet gas temperature is raised towards the 24 end of the experimental run (assuming the particles have dried sufficiently to 25 avoid collapse as the temperature is raised). 
1 Temperature measurements of the particles and the gas show a significant

2 cooling of the particles below the gas temperature (wet-bulb effect). This

3 gradually diminishes during drying and can be used to construct a drying

4 curve. Whilst not necessarily providing a highly accurate measurement of

5 drying, it is shown to be effective as a monitoring tool. The wet-bulb

6 depression is dependent on system pressure and rises as the pressure is

7 reduced. This study also indicates that highest temperature run $\left(-10{ }^{\circ} \mathrm{C}\right)$

8 produces the greatest drying rate. The resulting product is highly porous and

9 suffers little loss of protein solubility for $\beta$-lactoglobulin. In this research scale

10 experimental rig the gas is not recycled and this limits the sample mass to a

11 few grammes. Larger quantities could be produced using a system for

12 recycling the drying gas as performed by Leuenberger's group [11, 15]. Scale-

13 up of the process is likely to be complicated by the probable need to maintain

14 a shallow bed meaning that very large bed areas would be required to

15 produce quantities in a commercial scale. Nevertheless, the technique

16 appears to be able to produce powdered pharmaceutical and food products

17 more quickly than is normally possible by vacuum freeze-drying processes,

18 although each process is limited by different factors.

\section{NOMENCLATURE}

A surface area of particles

$\mathrm{m}^{2}$

$21 \quad h \quad$ heat transfer coefficient

$\mathrm{W} \mathrm{m} \mathrm{m}^{-2} \mathrm{~K}^{-1}$

$22 \quad k \quad$ constant in equation 2

$\mathrm{kg} \mathrm{K}^{-1} \mathrm{~s}^{-1}$

$23 \quad M \quad$ sample mass

$\mathrm{kg}$

$24 S P \quad$ mass fraction soluble protein 
$1 \quad T \quad$ temperature $\quad \mathrm{K}$

$2 \quad W \quad$ dry basis moisture content $\quad \mathrm{kg} \mathrm{kg}^{-1}$

\section{Greek letters}

$4 \lambda \quad$ latent heat of sublimation $\quad \mathrm{J} \mathrm{kg}^{-1}$

\section{Subscripts}

6 dry dry whey

$7 \quad g \quad$ outlet gas

$8 p$ particle

9 s spray-freeze-dried sample

$10 u \quad$ untreated sample

\section{ACKNOWLEDGEMENTS}

12 We gratefully acknowledge the Commonwealth Scholarship Commission, UK

13 for the award of Commonwealth Scholarship to CA. We also wish to 14 acknowledge the EPSRC (UK) for funding the development of the 15 experimental rig (grant number GR/N16662).

16 


\section{REFERENCES}

2 [1] Al-Hakim K., An investigation of spray-freezing \& spray-freeze-drying, PhD Thesis, Loughborough University, U.K., 2004.

[4] Anandharamakrishnan C., Rielly C.D., Stapley A.G.F., Loss of solubility of $\alpha$-lactalbumin and $\beta$-lactoglobulin during spray drying of whey proteins, LWT-Food Sci. Technol. 41 (2008) 270-277.

[5] Costantino H.R., Firouzabadian L., Hogeland K., Wu C., Beganski C., Carrasquillo K.G., Cordova M., Griebenow K., Zale S.E., Tracy, M.A., Protein spray-freeze-drying- effect of atomization condition on particle size and stability, Pharm. Res. 17 (2000) 1374-1380.

[6] Ferreira I.M.P.L.V.O., Cacote H., Detection and quantification of bovine, ovine and caprine milk percentage in protected denomination of origin cheese by reversed-phase high-performance liquid chromatography of beta-lactoglobulins, J. Chromatogr. A. 1015 (2003) 111-118.

[7] Ferreira I.M.P.L.V.O., Mendes E., Ferreira M.A., HPLC/UV analysis of protein in dairy products using a hydrophobic interaction chromatographic column, Anal. Sci. 17 (2001) 499-501. 
1 [8] Heldman D.R., An analysis of atmospheric freeze-drying, J. Food Sci. 39 (1974) 147-155.

3 [9] Hindmarsh J.P., Russell A.B., Chen X.D., Fundamentals of the sprayfreezing of foods-microstructure of frozen droplets, J. Food Eng. 78

6 [10] Leuenberger H., Spray-freeze-drying - the process of choice for low water soluble drugs?, J. Nanoparticle Res. 4 (2002) 111-119.

[11] Leuenberger H., Plitzko M., Puchkov M., Spray-freeze-drying in a fluidized bed at normal and low pressure, Drying Technol. 24 (2006) 711719.

[12] Maa Y.F., Nguyen P.A., Sweeney T., Shire S.J., Hsu C.C., Protein inhalation powders: spray drying vs spray-freeze-drying, Pharm. Res. 16 (1999) 249-255.

[13] Malecki G.J., Shinde P., Morgan A.I., Farkas D.F., Atmospheric fluidized bed freeze-drying, Food Technol. 24 (1970) 601-603.

[14] Meryman H.T., Sublimation freeze-drying without vacuum, Science 130 (1959) 628-629.

[15] Mumenthaler M., Leuenberger H., Atmospheric spray-freeze-drying: a suitable alternative in freeze-drying technology, Int. J. Pharm. 72 (1991) 97-110.

[16] Rogers S., Wu W.D, Saunders J., Chen X.D., Characteristics of milk powders produced by spray-freeze-drying, Drying Technol. 26 (2008) 404-412. 
1 [17] Rogers T.L., Hu J., Yu Z., Johnston K.P., Williams III R.O., A novel particle engineering technology: spray-freezing into liquid, Int. J. Pharm. 24 (2002) 93-100.

4 [18] Rogers T.L., Nelsen A.C., Sarkari M., Young T.J., Johnston K.P., Williams III R.O., Enhanced aqueous dissolution of poorly water soluble drug by novel particle engineering technology: spray-freezing into liquid with atmospheric freeze-drying, Pharm. Res. 20 (2003) 485-493.

8 [19] Sheu T.Y., Rosenberg M., Microstructure of microparticles consisting of

[20] Stapley A.G.F., Freeze-drying, in: Evans J.A. (Ed.), Frozen food science and technology, Blackwell, Oxford, UK, 2008, pp. 248-275.

12 [21] Wang Z.L., Finlay W.H., Peppler M.S., Sweeney L.G., Powder formation by atmospheric spray-freeze-drying, Powder Technol. 170 (2006) 45-52.

14 [22] Yu Z., Garcia A.S., Johnston K.P., Williams R.O., Spray-freezing into 15 liquid versus spray-freeze-drying: influence of atomization on protein aggregation and biological activity, Eur. J. Pharm. Biopharm. 27 (2006) 9-18. 
Table I. Effects of inlet gas temperatures of fluidized bed freeze dryer on moisture content, particle size and drying times. The error data represent one standard deviation from the mean.

\begin{tabular}{|c|l|l|l|l|}
\hline $\begin{array}{l}\text { Inlet gas } \\
\text { temperature } \\
\left({ }^{\circ} \mathbf{C}\right)\end{array}$ & $\begin{array}{l}\text { Fluidized } \\
\text { bed freeze } \\
\text { dryer } \\
\text { pressure } \\
\text { (bar) }\end{array}$ & $\begin{array}{l}\text { Average } \\
\text { moisture } \\
\text { content of } \\
\text { final } \\
\text { product } \\
\text { (wet basis) } \\
(\mathbf{\%})\end{array}$ & $\begin{array}{l}\text { Sauter } \\
\text { mean } \\
\text { Particle } \\
\text { diameter } \\
(\boldsymbol{\mu m})\end{array}$ & $\begin{array}{l}\text { Drying time } \\
(\mathbf{s})\end{array}$ \\
\hline$-10 \pm 1.0$ & 0.1 & $8.1 \pm 2.27$ & $480 \pm 53$ & 3600 \\
\hline$-15 \pm 1.0$ & 0.1 & $9.5 \pm 0.43$ & $393 \pm 75$ & 3900 \\
\hline$-30 \pm 1.0$ & 0.1 & $14.0 \pm 0.61$ & $412 \pm 4$ & 6000 \\
\hline
\end{tabular}


Figures
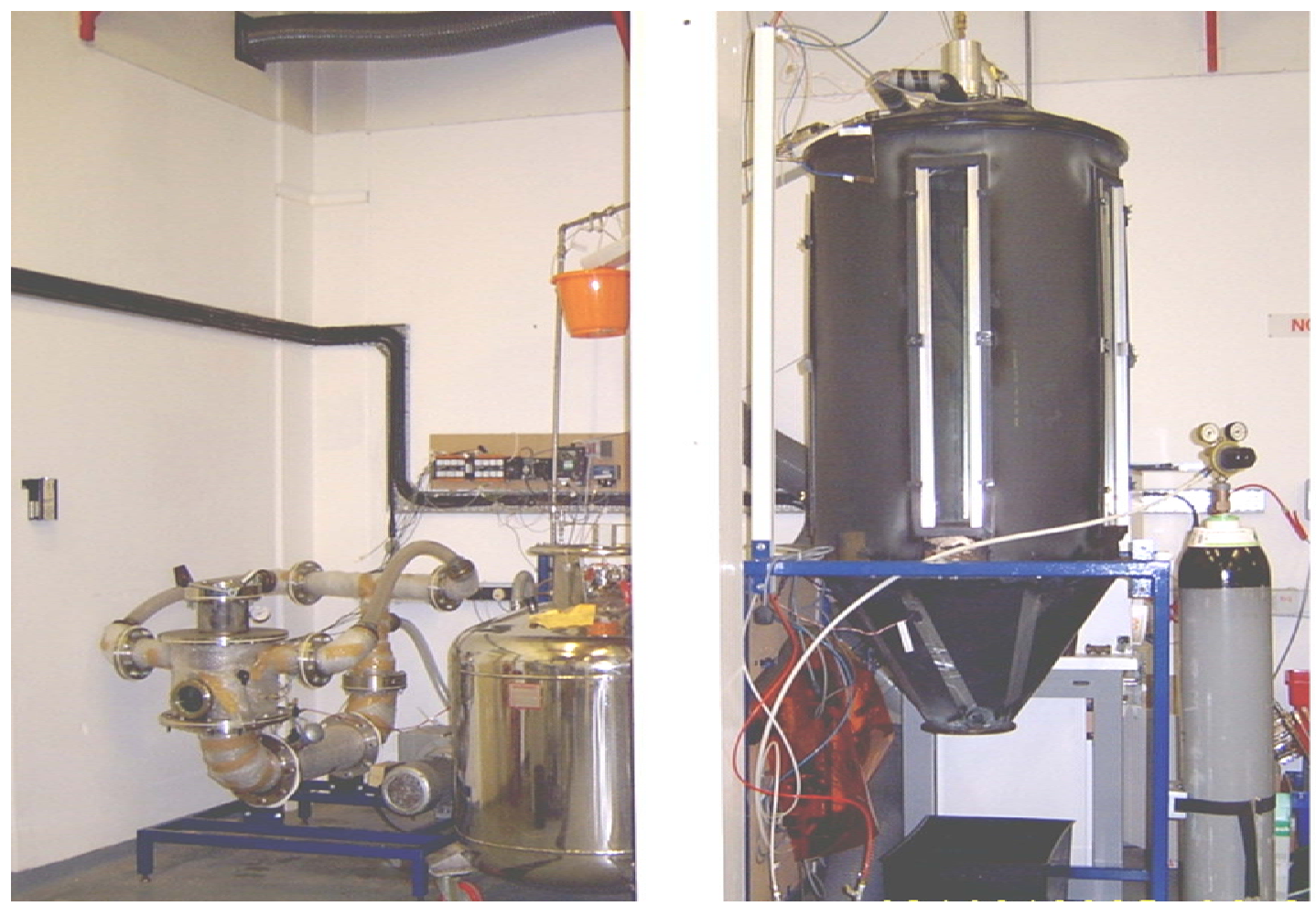

Fig. 1. The spray-freeze-drying apparatus used in these experiments. Sprayfreezing initially occurs in the large (black) chamber located on the right of the photo. The spray frozen particles are collected from the base of this chamber and transferred to the sub-atmospheric fluidized bed freeze-drying apparatus on the left of the photo. 


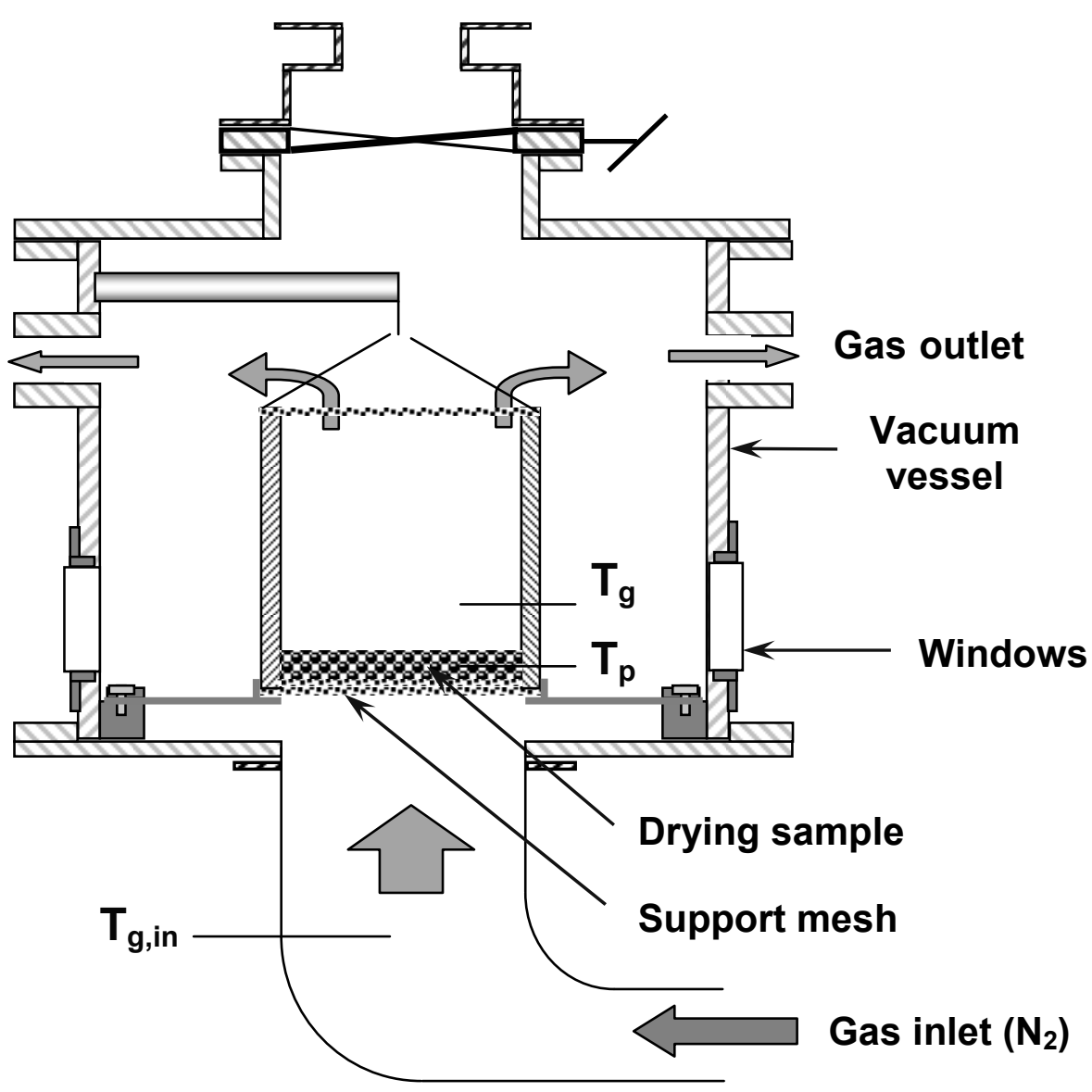

Fig. 2. Schematic diagram of the sub-atmospheric fluidized bed freeze-dryer. 


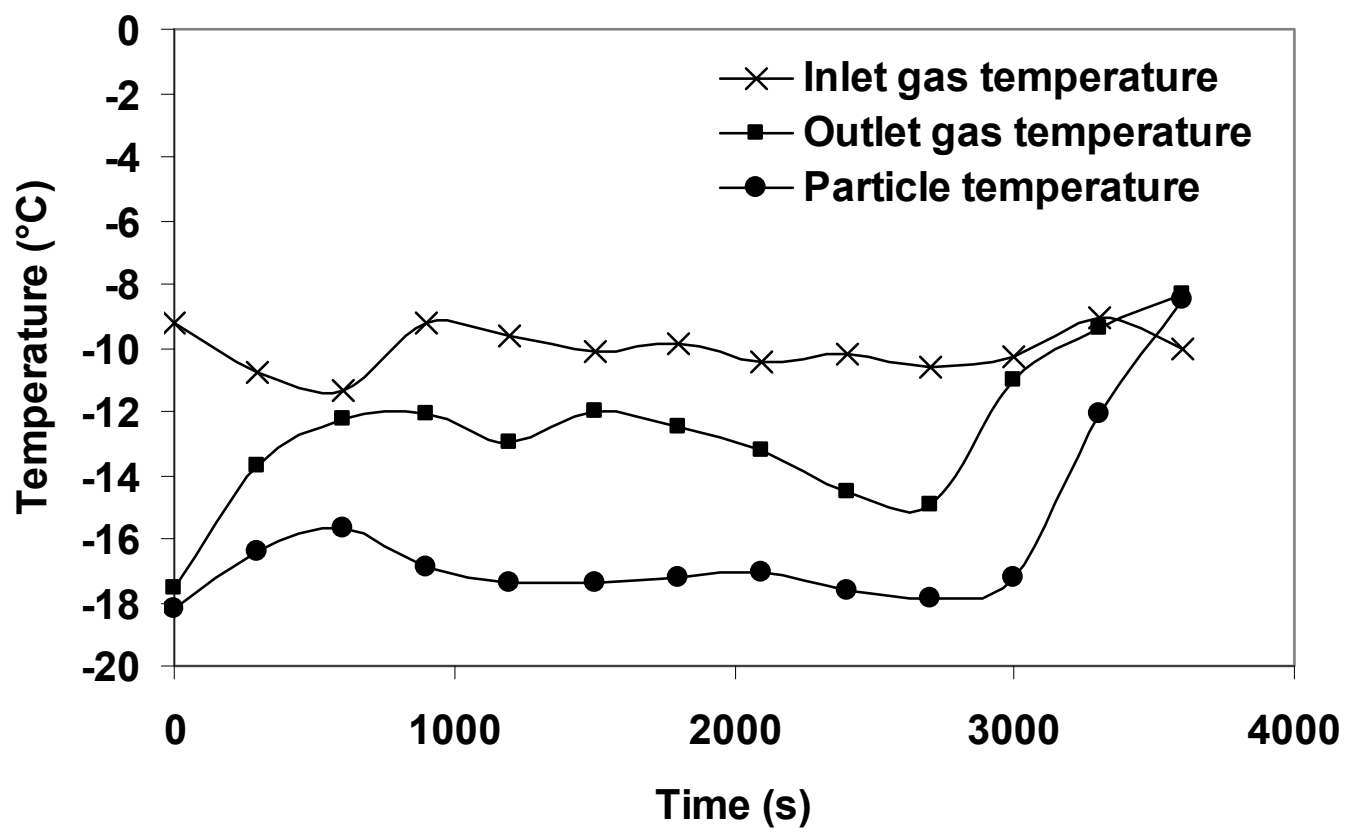

Fig. 3.

Inlet gas, outlet gas and particle temperatures during the freeze-drying of whey at $10 \pm 1.0^{\circ} \mathrm{C}$ and 0.1 bar.

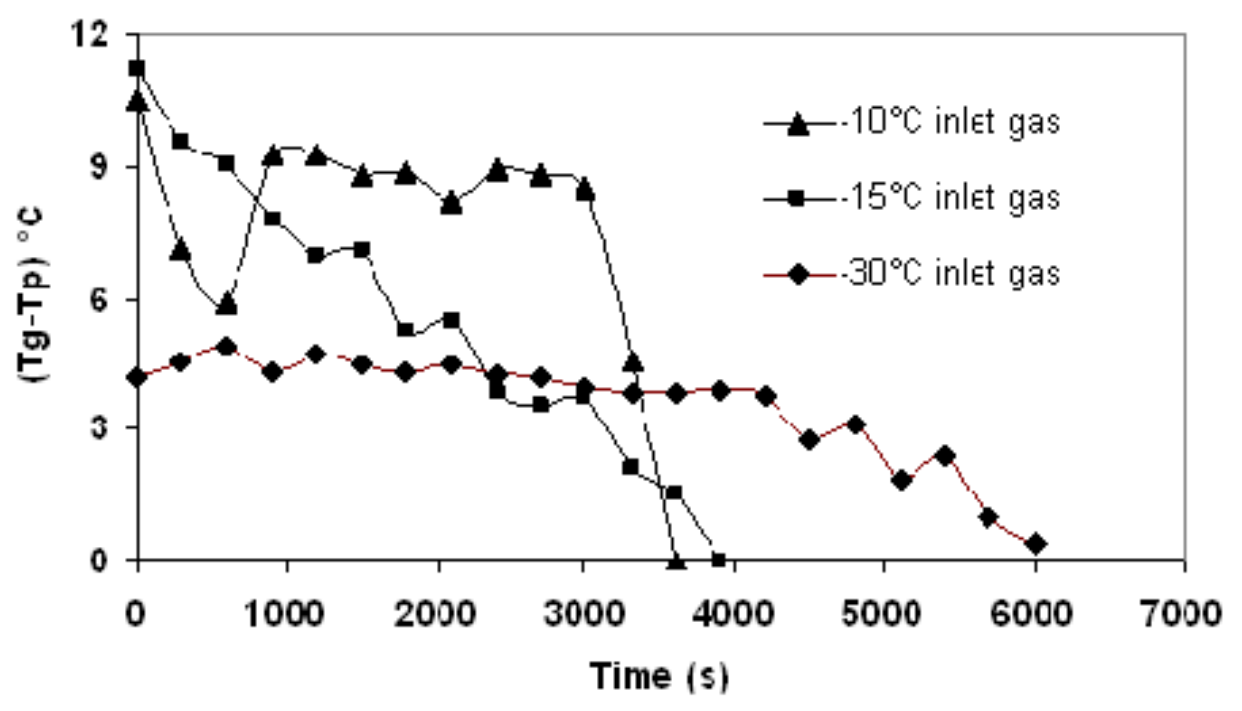

Fig. 4. Wet bulb depression (difference of outlet gas and particle temperature) versus time during the freeze-drying of whey at 0.1 bar. 


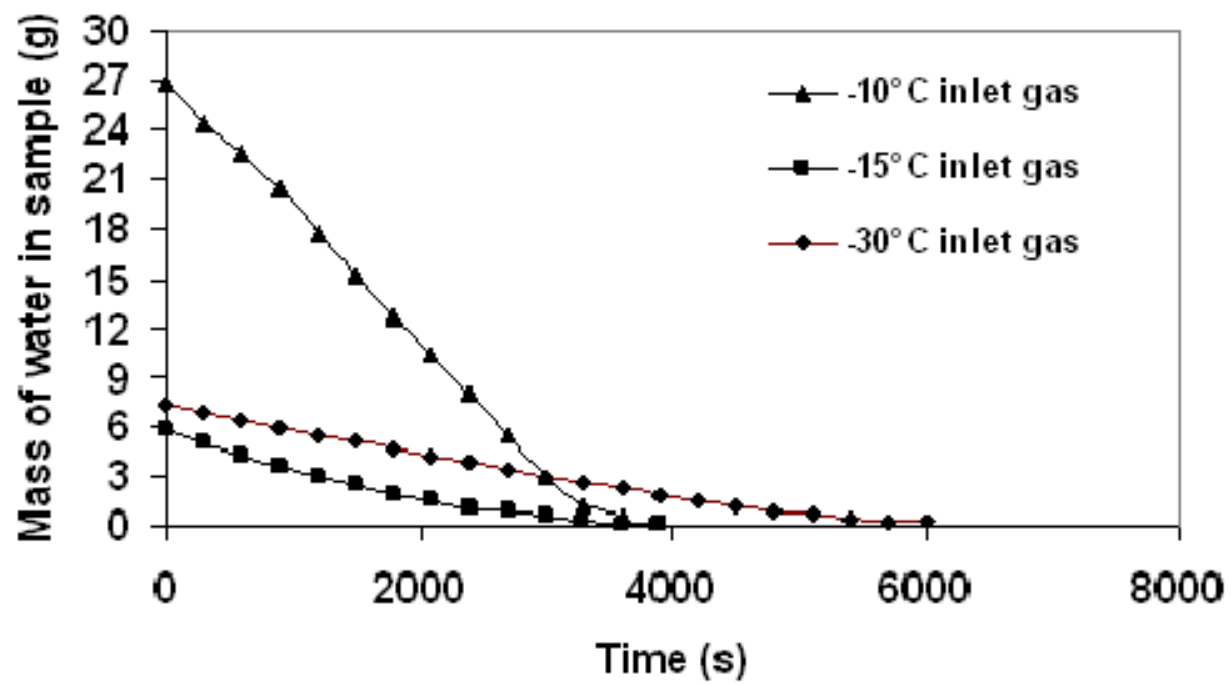

Fig. 5. Drying curve calculated from the temperature data shown in Figure 4.

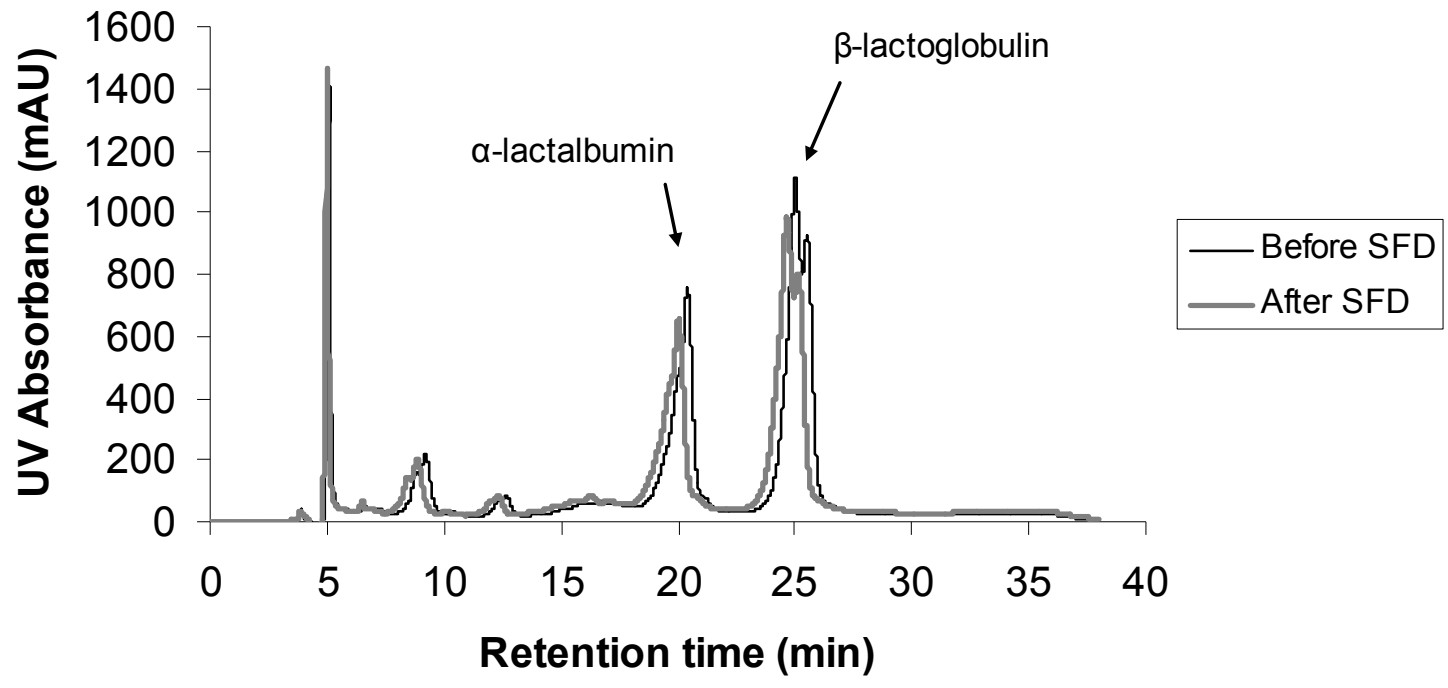

Fig. 6. RP-HPLC chromatograms of spray-freeze-dried whey protein isolate before and after spray freeze drying (SFD). 


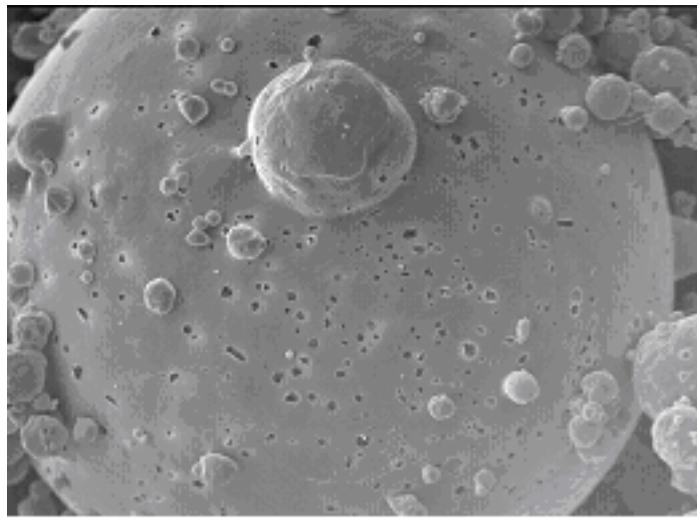

(a)

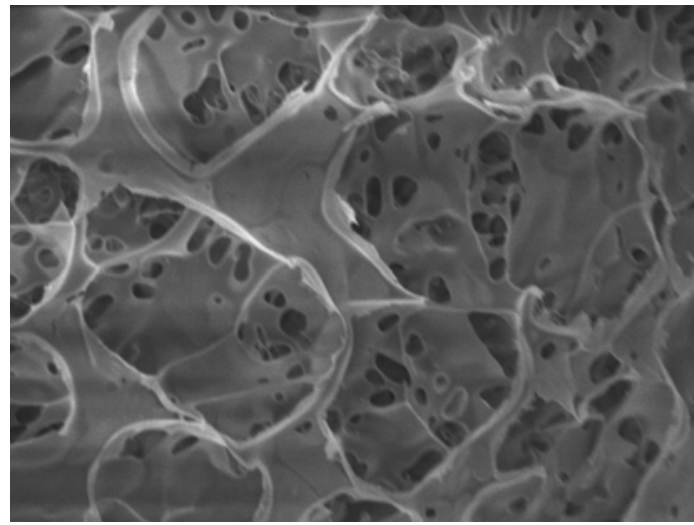

(c)

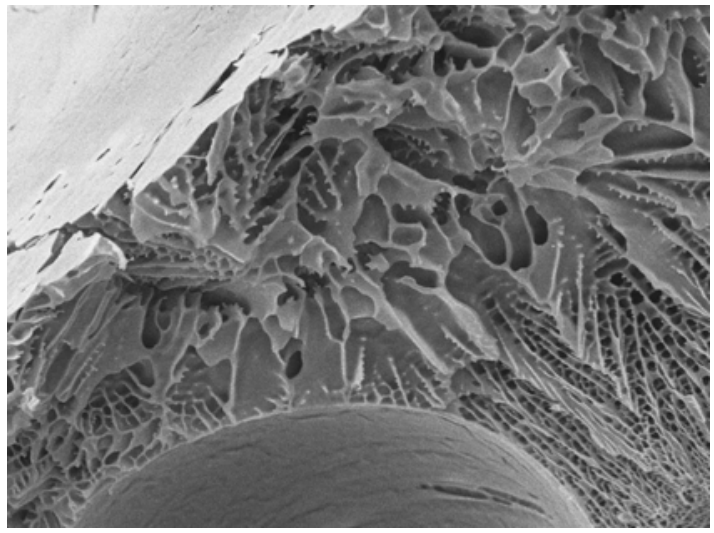

(e)
$40 \mu \mathrm{m}$

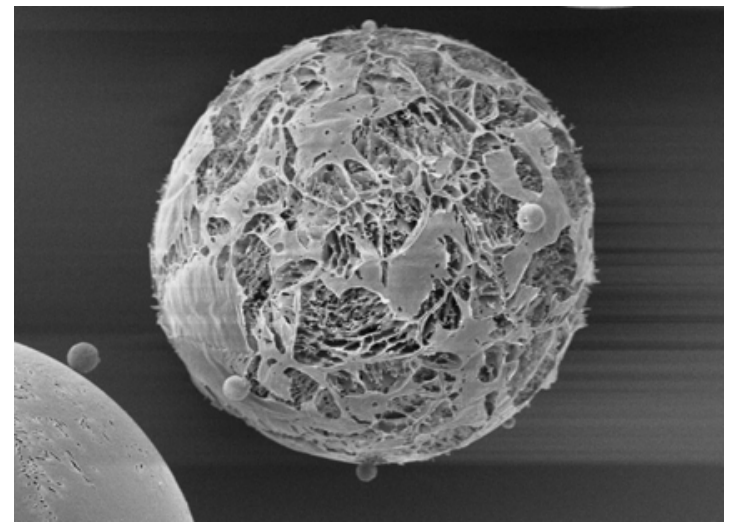

(b)

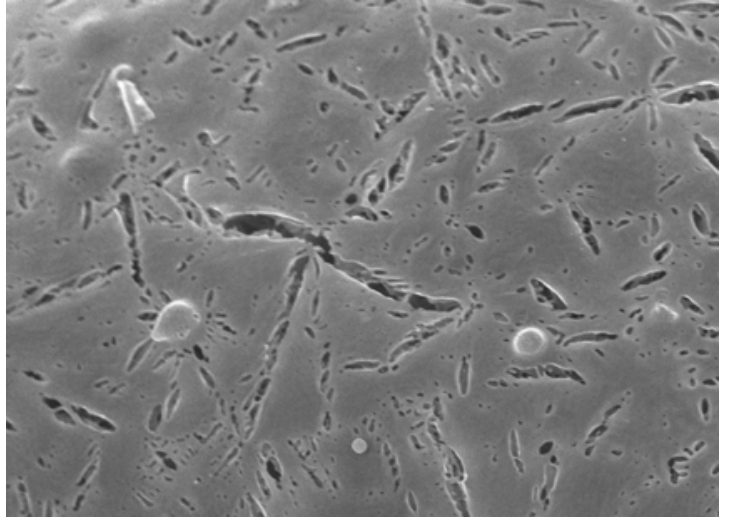

(d)

$40 \mu \mathrm{m}$

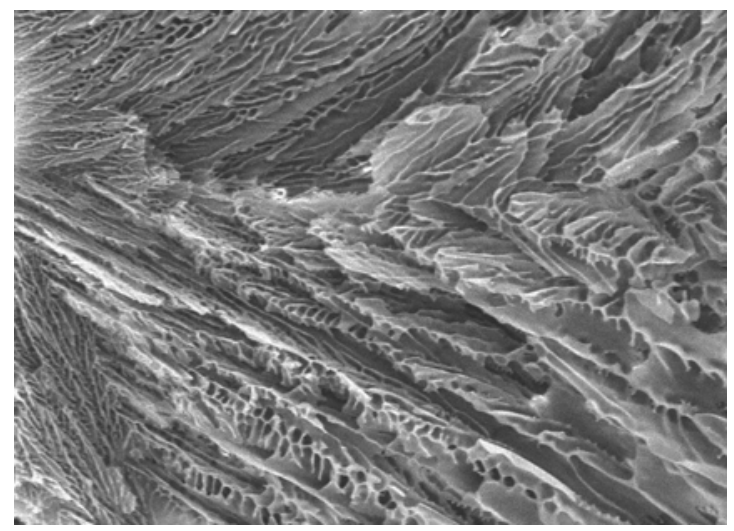

(f)

Fig. 7. SEM images of spray-freeze-dried whey protein isolate powder. The widths of the images are $140,220,83,96,90$ and $96 \mu \mathrm{m}$ respectively. 